\title{
14th International Conference on Computational Management Science
}

\author{
Rosella Giacometti ${ }^{1}$ - Berç Rustem ${ }^{2}$
}

Published online: 21 January 2019

๑) Springer-Verlag GmbH Germany, part of Springer Nature 2019

This issue consists of a selection of the presentations at the Fourteenth International Conference on Computational Management Science, held at the University of Bergamo, May 30-31, June 1, 2017.

The focus of the conference this year was to cover the areas Pricing, Risk, and Optimization in Management Science. Accordingly, the special issue comprises fourteen papers on optimization, power and financial optimization.

The conference was organised by the University of Bergamo, in conjunction with the Georgia Institute of Technology and the journal Computational Management Science. The Programme Committee consisted of: Giorgio Consigli (Chair), Francesca Maggioni, Rosella Giacometti, Sergio Ortobelli (all from the University of Bergamo) and of the following scholars: Shabbir Ahmed (GeorgiaTech, USA); Rita D'Ecclesia (U. La Sapienza, IT); Michael Dempster (U. Cambridge, UK); Laureano F. Escudero (U. Rey Juan Carlos, ES); Csaba Fábián (Kecskemét College, HU); Paolo Falbo (U. Brescia, IT); Aaron Kim (Stony Brook U., USA); Anton Kleywegt (GeorgiaTech, USA); Miloš Kopa (Charles U, CZR); Daniel Kuhn (EPFL, CH); Abdel Lisser (U. Paris Sud, FR); Enza Messina (U. Milano Bicocca, IT); Ruth Misener (Imperial College, UK); Panos Pardalos (U. Florida, USA); Sandra Paterlini (EBS, GE); Georg Pflug (U. Vienna, AUT); Berç Rustem (Imperial College, UK); Rüdiger Schultz (U. Duisburg-Essen, GE); Alex Weissensteiner (U. Bolzano, IT).

The University of Bergamo Organising Committee consisted of Giorgio Consigli; Rosella Giacometti; Adriana Gnudi; Mohammad Hosseinzadeh; Davide Lauria; Francesca Maggioni; Vittorio Moriggia; Sergio Ortobelli; Roberto Pinto; Gabriele Torri; Maria Vespucci; Sebastiano Vitali.

Rosella Giacometti

rosella.giacometti@unibg.it

Berç Rustem

b.rustem@imperial.ac.uk

1 Department of Management, Economics and Quantitative Methods, University of Bergamo, Bergamo, Italy

2 Department of Computing, Imperial College London, London SW7 2AZ, UK 
On May 29, 2017, the day before the conference, a workshop entitled "Facing risk ... sometimes with negative interest rate" was organised in memory of Professor Marida Bertocchi. Her close friends: Franco Archetti. Elio Canestrelli, Georg Pflug, Zari Rachev, Grazia Speranza, Giovanni Zambruno, Stavros Zenios, Bill Ziemba, Francesco Zirilli, presented their memories of research and life with Marida.

We should like to thank all persons who helped to organize the conference. We are indebted to the organisers of the invited sessions and the members of the Programme Committee for the success of the conference and the quality of submissions to this special issue.

Publisher's Note Springer Nature remains neutral with regard to jurisdictional claims in published maps and institutional affiliations 